\title{
Uso de antirreumáticos en covid-19 desde la hidroxicloroquina hasta la anakinra pasando por tocilizumab y baricitinib: Una revisión de la literatura
}

\section{Use of antirheumatic drugs in covid-19 from hydroxychloroquine to anakinra through tocilizumab and baricitinib: A review of the literature}

\section{RESUMEN}

Actualmente nos encontramos en una pandemia mundial causada por el coronavirus 2019 o COVID-19, presentando diferentes desafíos para el sistema de salud debido a que no se cuenta aún con alguna vacuna ni con un tratamiento que haya demostrado su eficacia en totalidad, siendo el manejo actual preventivo y de soporte. Por lo que, en esta revisión se estudiará a los fármacos antirreumáticos más resaltantes que tengan un probable efecto farmacológico, como son la hidroxicloroquina, el tocilizumab, el anakinra y el baricitinib, frente al COVID-19. Se espera que brinde apoyo para futuros tratamientos e investigaciones sobre la enfermedad.

Palabras Clave: COVID-19; Hidroxicloroquina; Tocilizumab; Anakinra; Baricitinib; Agentes antirreumáticos. (Fuente: DeCS-BIREME).

\begin{abstract}
We are currently in a global pandemic caused by the coronavirus 2019 or COVID19 , presenting different challenges for the health system due to the fact that there is still no vaccine or a treatment that has proven its effectiveness in its entirety, being the management current preventive and supportive. Therefore, this review will study the most prominent antirheumatic drugs that have a probable pharmacological effect, such as hydroxychloroquine, tocilizumab, anakinra and baricitinib, against COVID-19. It is expected that they will provide support for future treatments. and research on the disease.
\end{abstract}

Keywords: COVID-19; hydroxychloroquine; tocilizumab; anakinra; baricitinib; antirheumatic agents. (Fuente: DeCS-BIREME).
FILIACIÓN

1. Facultad de Medicina Humana, Universidad Privada Antenor Orrego, Trujillo, Perú

a. Bachiller de Medicina Humana

b. Magister en Medicina

c. Doctor en Salud Pública

ORCID:

1. RosaAlejandra Salas Bolaños 0000-0002-8782-0575

2. David Ezequiel Sevilla Rodríguez 0000-0002-8410-5787

3. Abel Salvador Arroyo Sánchez 0000-0001-6022-6894

\section{CORRESPONDENCIA}

Rosa Alejandra Salas Bolaños. Vasconcellos - 935 - Urb. Las Quintanas Telf. 980721075

EMAIL

rsalasb@upao.edu.pe

CONFLICTOS DE INTERÉS

Los autores niegan conflictos de interés.

\section{FINANCIAMIENTO}

Autofinanciamiento.

REVISIÓN DE PARES

Recibido:

Aceptado:

\section{COMO CITAR}

Salas-Bolaños, R., Sevilla-Rodriguez, D., \& Arroyo-Sánchez, A. Uso de antirreumáticos en covid-19 desde la hidroxicloroquina hasta la anakinra pasando por tocilizumab y baricitinib: Una revisión de la literatura. Revista Del Cuerpo Médico Del HNAAA, 2021.14(1), 11-22. https://doi.org/10.35434/rcmhnaaa.2021.141. .821

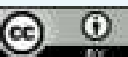

Esta obra está bajo una Licencia Creative Commons Atribución 4.0 Internacional. Versión Impresa: ISSN: 2225-5109 Versión Electrónica: ISSN: 2227-4731 Cross Ref. DOI: 10.35434/rcmhnaaa OJS: https://cmhnaaa.org.pe/ojs 


\section{INTRODUCCIÓN}

En la actualidad, nos encontramos pasando por una crisis sanitaria mundial debido a la enfermedad del coronavirus 2019 o COVID - 19 causada por el coronavirus tipo 2 del síndrome respiratorio agudo grave (SRAS) (en inglés: Severe Acute Respiratory Syndrome, SARS) está una enfermedad respiratoria viral causada pororiginario de China ${ }^{(1)}$.

El COVID-19 se transmite principalmente por la vía aérea ingresando por inhalación a la nariz o la boca a través de la tos, estornudos, gotas respiratorias o aerosoles producidos por los pacientes infectados. Ingresando al organismo a través de la unión al ACE-2, lo que puede influir en su variada expresión; por lo que su presentación clínica es variada siendo desde asintomática hasta mortal, dependiendo además de otros factores predisponentes ${ }^{(2)}$, como son el sexo masculino, la edad avanzada, la presencia de comorbilidades como hipertensión, diabetes, enfermedad cardiovascular, enfermedad cerebrovascular y enfermedad renal crónica, en pocos casos se ha visto relacionado a EPOC o fumar ${ }^{(3)}$, además de otros factores evidenciados como la relación del grupo sanguíneo tipo A y la del tipo 0 , en la mayor o menor morbimortalidad respectivamente ${ }^{(4)}$. Estos factores pueden hacer que la infección pase de ser un "simple resfriado" a un cuadro de síndrome de dificultad respiratoria aguda o SDRA con falla multiorgánica, terminando finalmente en la muerte del paciente $^{(5)}$.

Este caso anterior se puede explicar por la presencia de una tormenta de citoquinas, similar al Síndrome de Activación del Macrófago o SAM y al Síndrome de linfohistiocitosis hemofagocítica o HLH que se evidencian también en actividad de enfermedades reumáticas ${ }^{(6)}$, debido a la liberación descontrolada de citocinas inflamatorias como la IL-1B, IL-6 o la proteína quimioatrayente de monocitos 1 , asociado a aumento de ferritina sérica y disminución de la función de los linfocitos NK, causando una inmunosupresión profunda, por lo que algunos fármacos antirreumáticos podrían disminuir la exacerbación de la enfermedad. Estos dos eventos previamente mencionados podrían ser controlados por el tocilizumab al bloquear la LL-6 y el anakinra al bloquear la IL- $1^{(7)}$.

Además, la hidroxicloroquina es un antimalárico que se ha usado en enfermedades reumáticas debido a su participación al disminuir la producción de citoquinas causantes de la respuesta inflamatoria, también inhibe la activación de algunos $\operatorname{TLR}^{(8)}$, pudiendo disminuir así el efecto de la tormenta de citoquinas causado por el COVID-19 ${ }^{(9)}$.

Otro fármaco que se encuentra evaluado es el baricitinib, el cual inhibe a los JAK 1 y 2 al impedir la unión de esto con el ATP, haciendo que no se fosforilen ni se activen los transductores de señal y activadores de la transcripción o STAT, bloqueando de esta manera la señalización de citoquinas $^{(10)}$.

La importancia de controlar estos eventos es debido a que la tormenta de citoquinas se ha visto relacionada con un pronóstico desfavorable en los pacientes con COVID-19, asociado a un mayor riesgo de mortalidad, presentando muchos de ellos falla multiorgánica ${ }^{(11)}$.
Nuestro país no ha se ha visto ajeno a esta enfermedad, presentando su primer caso el 06 de marzo, y desde esa fecha se ha mantenido un aumento constante tanto en número de contagiados como en número de muertos, lo cual ha tratado de ser controlado con las medidas que ha venido tomando el gobierno ${ }^{(12)}$. Al no tener un tratamiento efectivo, las medidas preventivas han tomado importancia en el control de la enfermedad realizando diagnósticos tempranos, manteniendo a la población informada, y estableciendo disposiciones sociales con adecuadas medidas de protección ${ }^{(13)}$. Por lo que es importante determinar la eficacia de los nuevos tratamientos farmacológicos que se están estudiando debido a que en nuestro país gran parte de nuestra población presenta diversos factores predisponentes que complicarían la infección por covid-19 y aumentarían el riesgo de mortalidad. Si bien los resultados de los diferentes estudiados realizados sobre estos fármacos son variados, es necesario realizar un análisis y determinar conclusiones críticas para ellos.

\section{METODOLOGÍA}

Se realizó una búsqueda avanzada en las bases de datos hispanoamericanas como Scielo y Lilacs, también en bases de datos internacionales como ScienceDirect. Además, se apoyó la investigación usando los motores de búsqueda de PUBMED y Google Académico. Las palabras claves usadas fueron "COVID - 19" and "antirheumatic agents", "COVID 19 " and "hydroxychloroquine", "COVID - 19" and "anakinra", "COVID - 19" and "tocilizumab", y "COVID - 19" and "baricitinib". Los artículos que se incluyeron en la revisión fueron artículos que presentaran las palabras clave en el título, que se encontraran escritos en español o inglés, realizados este año, y los artículos a los cuales se tenía el acceso gratuito; por otro lado, los artículos que se excluyeron fueron los que tenían estudios realizados en animales, que no tuvieran los resultados publicados o que se encontraran en revisión para su publicación. Los estudios que se consideraron en la revisión fueron los artículos de revisión, estudios de cohorte, estudios de casos y controles, reportes de casos, estudios multicéntricos y estudios experimentales controlados y no controlados.

\section{HIDROXICLOROQUINA}

La hidroxicloroquina es una aminoquinolina, menos tóxica y más soluble que la cloroquina, usado habitualmente en el tratamiento de malaria y en algunas enfermedades reumáticas ${ }^{(14)}$. Produce un aumento del $\mathrm{pH}$ y tiene efectos antivirales, además de un efecto modulador sobre las células activadas. Tiene gran afinidad a la melanina por lo que puede adherirse a tejidos con melanina como la piel y los ojos, pudiendo llegar a causar retinopatía en este último ${ }^{(15)}$. Los efectos inmunomoduladores y antiinflamatorios se basan al inhibir al NFkB de los macrófagos, disminuyendo de esta manera la generación de citocinas pro inflamatorias como la IL-1, TNF-a, IL - 6, IFN - y; además reduce el procesamiento de los ligandos endógenos y exógenos a través de lisosomas y endosomas, disminuyendo así la disponibilidad de antígenos procesados para la presentación del complejo de histocompatibilidad - receptores de las células $T$, reduciendo la activación de la inmunidad celular. Esto podría ser la razón 

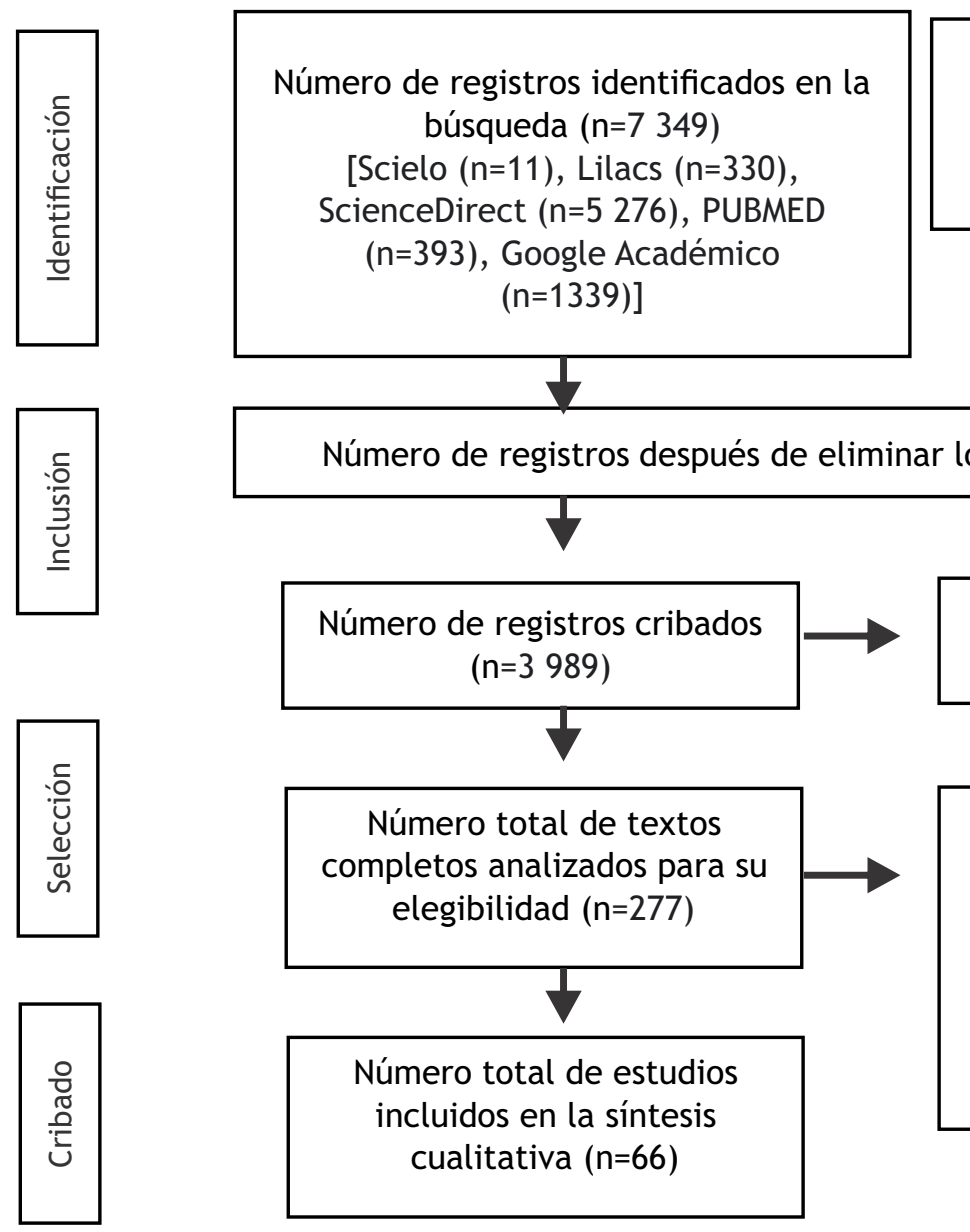

Número de textos completos excluidos $(\mathrm{n}=211)$ [Textos sin resultados publicados $(n=89)$, textos con información repetida $(n=54)$, textos en formato de prepublicación $(n=68)]$ adicionales identificados en otras fuentes $(n=1)$

Figura 1. Diagrama de flujo de la búsqueda en base a la Declaración PRISMA

por la cual funcionaría frente al COVID - 19 y a la tormenta de citocinas que este causaría, otros mecanismos que se han planteado es el bloqueo de la entrada del virus al disminuir la disponibilidad de los receptores ACE II o al disminuir la captación de nanopartículas por los macrófagos o de los endosomas al neutralizar su $\mathrm{pH}$, también se ha planteado la capacidad de disminuir la formación del virión ${ }^{(16)}$.

La hidroxicloroquina tiene como efectos adversos más comunes a los síntomas gastrointestinales como náuseas o malestar abdominal, pero dentro de uno de los pocos frecuentes se encuentran la insuficiencia hepática fulminante y la cardiotoxicidad, esto se puede presentar debido a que cuenta con una larga vida media y un gran volumen de distribución; sin embargo, la hidroxicloroquina cuenta con un buen perfil de seguridad presentado solo toxicidad en casos de tratamiento crónico $^{(17)}$ considerado a partir de los 5 años, o en caso de sobredosis cuando la dosis media diaria es $>0,5 \mathrm{mg} / \mathrm{kg}$; además la disfunción hepática o renal puede agravar los efectos adversos debido a que disminuye su excreción ${ }^{(18)}$. Se recomienda evitar su uso con fármacos digitálicos o antiarrítimicos clase la o clase III para evitar alteraciones en la conducción cardíaca, así como también se debe evitar su uso con quinolonas o macrólidos ${ }^{(19)}$.
En Estados Unidos se llevó a cabo un estudio observacional retrospectivo que incluyó a 2541 pacientes con COVID - 19, de los cuales 1202 recibieron solo tratamiento con $400 \mathrm{mg}$ de hidroxicloroquina cada 12 horas por un día, seguido de 200 mg por 2 a 5 días; 783 pacientes recibieron además de la hidroxicloroquina tratamiento con $500 \mathrm{mg}$ de azitromicina cada 24 horas por un día, seguido de 250 mg diarios por 4 días; 147 pacientes recibieron azitromicina sola y 409 pacientes recibieron otro tratamiento. En los resultados se encontró que la mortalidad global fue del $18,1 \%$, de la cual $20,1 \%$ corresponde al grupo del tratamiento con azitromicina e hidroxicloroquina, $13,5 \%$ a los que se trataron solo con hidroxicloroquina, $22,4 \%$ a los que se trataron con azitromicina sola y $26,4 \%$ a los que recibieron otro tratamiento. Además, se encontró que la hidroxicloroquina reduce el riesgo de mortalidad en un $66 \%$ y en combinación con azitromicina en un $71 \%{ }^{(20)}$.

En los Países Bajos también se llevó un estudio de cohorte observacional, comparando el uso de tres tratamientos diferentes en 1064 pacientes con COVID - 19, el primero era con hidroxicloroquina que abarcó a 189 pacientes, el segundo con cloroquina que tuvo a 377 pacientes, y el tercero con ningún tratamiento que contó con 489 pacientes. En el estudio no se encontró ningún efecto significativo en la 
Revista del Cuerpo Médico del HNAAA, Vol 14 (1) - 2021

mortalidad al usar hidroxicloroquina o cloroquina, pero si se encontró una reducción del $53 \%$ en el riesgo de ingreso a $\mathrm{UCI}$ solo en el grupo que uso el tratamiento con hidroxicloroquina ${ }^{(21)}$.

En Arabia Saudita se realizó un estudio de cohorte retrospectivo evaluando a 161 pacientes con COVID - 19, de los cuales 95 pacientes recibieron tratamiento con hidroxicloroquina y 66 pacientes recibieron tratamiento estándar. Se encontró que tanto la estancia hospitalaria como la necesidad de ingreso a $\mathrm{UCl}$ fue menor en los pacientes tratados con hidroxicloroquina, teniendo a un $8.6 \%$ frente a un $10,7 \%$ para la primera comparación, y a un $3.1 \%$ frente a un $9,1 \%$ para la segunda ${ }^{(22)}$. En Italia se realizó un estudio multicéntrico observacional con 3451 pacientes con COVID19 , de ellos el $76,3 \%$ recibió tratamiento con hidroxicloroquina y los demás recibieron tratamiento estándar. Obteniendo como resultado que los pacientes tratados con hidroxicloroquina presentaron un $30 \%$ menos de riesgo de mortalidad, especialmente aquellos que al momento del ingreso tuvieron la Proteína $\mathrm{C}$ reactiva elevada $^{(23)}$. En Bélgica también se realizó un estudio observacional de cohorte con 8075 pacientes con COVID - 19, a quienes se les dividió en dos grupos, un grupo de 3533 pacientes solo recibió tratamiento de soporte y el otro grupo de 4542 pacientes recibió tratamiento con $2400 \mathrm{mg}$ en total de hidroxicloroquina durante 5 días.

Se encontró que la estancia hospitalaria fue similar en ambos grupos, pero a pesar de que los pacientes tratados con hidroxicloroquina tenían una enfermedad más severa evidenciada en los hallazgos radiológicos, de imagen y necesidad de soporte ventilatorio en UCI, la tasa de letalidad de los pacientes en este grupo fue de $17,7 \%$ siendo menor en comparación con el grupo que no recibió tratamiento con hidroxicloroquina siendo en ellos de $27,1 \%$. Esto se continuó evidenciando 40 días después, presentando el tratamiento con hidroxicloroquina un riesgo de mortalidad del 19,1\%, mientras que el grupo con tratamiento de soporte presentó un $26,5 \%$, también se identificó que los pacientes que recibieron tratamiento dentro de los primeros 5 días de iniciado los síntomas tuvieron mejor pronóstico en ambos grupos que los que se demoraron más en recibir tratamiento ${ }^{(24)}$.

En Estados Unidos se realizó un estudio retrospectivo, abarcando a 807 pacientes con diagnóstico de COVID - 19, los cuales se dividieron en tres grupos, el primero conformado por 198 pacientes recibió tratamiento con hidroxicloroquina con una dosis media de $400 \mathrm{mg}$ por 5 días, el segundo con 214 pacientes recibió tratamiento combinado de hidroxicloroquina y azitromicina, y el tercero con 395 pacientes recibió tratamiento estándar. En el cual se encontró que el riesgo de necesidad de soporte ventilatorio fue igual en los tres grupos, pero el riesgo de muerte fue mayor en el grupo que solo recibió tratamiento con hidroxicloroquina, además la estancia hospitalaria fue mayor en el grupo que recibió el tratamiento combinado seguido por el grupo que solo recibió tratamiento con hidroxicloroquina ${ }^{(25)}$. Por otro lado, en Turquía se realizó un estudio retrospectivo para evaluar los cambios electrocardiográficos luego del tratamiento combinado de 5 días con hidroxicloroquina y azitromicina, abarcando a 109 pacientes con COVID - 19

La dosis del tratamiento fue en el primer día $400 \mathrm{mg}$ de hidroxicloroquina vía oral y luego se dieron $200 \mathrm{mg}$ cada 2 horas vía oral, para azitromicina fue de $500 \mathrm{mg}$ el primer día como dosis de carga y luego $250 \mathrm{mg}$ una vez al día por 4 días. En los resultados no se encontró diferencias significativas en los electrocardiogramas, tampoco se encontró empeoramiento de la función cardíaca ni muerte por causa cardíaca ${ }^{(26)}$. Mientras que en Francia se llevó a cabo un ensayo clínico no aleatorizado con 36 pacientes con COVID 19 , de los cuales 20 pacientes recibieron tratamiento diario con $600 \mathrm{mg}$ de hidroxicloroquina y en algunos casos fue necesario adicionar azitromicina dependiendo de su evolución clínica, mientras que el otro grupo recibió tratamiento de soporte. Se encontró que el tratamiento con hidroxicloroquina se asocia a una reducción significativa de la carga viral y su efecto se ve reforzado con la adición de azitromicina ${ }^{(27)}$. Esto se ve reforzado con otro estudio en Francia, en el cual se evaluó la interacción in vitro de hidroxicloroquina y azitromicina en el tratamiento del COVID

19, encontrando que ambos fármacos tienen efecto sinérgico disminuyendo la replicación viral significativamente en el COVID - $19^{(28)}$.

En Egipto se realizó un ensayo clínico controlado aleatorio multicéntrico, incluyendo a 194 pacientes con COVID - 19 que se separaron en 97 que recibieron tratamiento con $400 \mathrm{mg}$ de hidroxicloroquina vía oral cada 12 horas por el primer día, seguido de 200 mg cada 12 horas más tratamiento estándar por 15 días y otros 97 que solo recibieron tratamiento estándar por 15 días. En el cuál se evaluó la recuperación en el día 28 , la necesidad de ventilación mecánica y la muerte; sin embargo, el tratamiento agregado con hidroxicloroquina no presentó disminución de la reducción de la mortalidad o del riesgo del requerimiento de ventilación mecánica, no habiendo diferencia significativa para ninguna de las valoraciones entre los dos grupos ${ }^{(29)}$. De la misma manera en Noruega se hizo un ensayo clínico controlado aleatorizado con 53 pacientes con COVID - 19, separados en 27 pacientes que recibieron tratamiento con hidroxicloroquina en dosis de $400 \mathrm{mg}$ dos veces al día durante 7 días más tratamiento estándar y 26 pacientes que solo recibieron tratamiento estándar. En los resultados no se encontró diferencia significativa en la disminución de la carga viral orofaríngea, ni en la estancia media hospitalaria, ni en el riesgo de mortalidad, ni en el estado clínico a los 14 días ${ }^{(30)}$.

En China se realizó un ensayo clínico controlado aleatorizado que abarcó a 150 pacientes con COVID - 19, de los cuales 75 pacientes recibieron tratamiento con $1200 \mathrm{mg}$ de hidroxicloroquina dosis de carga por 3 días y luego $800 \mathrm{mg}$ al día por 2 o 3 semanas dependiendo de la gravedad de la enfermedad más tratamiento estándar y los otros 75 recibieron solo tratamiento estándar. Se evaluó la conversión negativa de la enfermedad a los 28 días la cual no presento diferencia significativa entre los dos grupos, pero el grupo que recibió hidroxicloroquina presento un porcentaje de $30 \%$ de efectos adversos siendo mayor que el otro grupo el cuál se encontró en $9 \%$, el efecto adverso más frecuente fue la diarrea y el más grave, pero menos común fue la infección asociada de vías respiratorias superiores $\left(^{31)}\right.$. Por otro lado, en Canadá y Estados Unidos se realizó un ensayo clínico 
Revista del Cuerpo Médico del HNAAA, Vol 14 (1) - 2021

aleatorizado controlado con 491 pacientes con COVID - 19 sintomático no hospitalizados que eran atendidos de manera ambulatoria, de los cuales 244 recibieron $800 \mathrm{mg}$ de hidroxicloroquina el primer día seguido de $600 \mathrm{mg}$ en 6 a 8 horas y luego $600 \mathrm{mg}$ diarios por 4 días más, mientras que 247 pacientes recibieron placebo. Se observó que el cambio de la gravedad de los síntomas no presento diferencias entre los dos grupos, pero en el día 14 solo el $24 \%$ de los pacientes con hidroxicloroquina presentaban síntomas mientras que del otro grupo era el $30 \%$, además ocurrieron 10 hospitalizaciones en el grupo que recibió placebo en comparación con 4 hospitalizaciones que ocurrieron en los pacientes con hidroxicloroquina, la tasa de mortalidad fue igual en ambos grupos, por último los efectos adversos se presentaron en mayor porcentaje ,43\% frente a $22 \%$, en el grupo que recibió hidroxicloroquina siendo los más frecuentes los síntomas gastrointestinales ${ }^{(32)}$.

\section{TOCILIZUMAB}

El tocilizumab es un anticuerpo monoclonal humanizado antagonista de la interleucina - 6 , actúa al inhibir la unión de esta interleucina con sus receptores, tanto solubles (sIL-6R) como los unidos a la membrana (mIL6R), empleado debido a su potente efecto antiinflamatorio, usado como tratamiento para diferentes enfermedades como la artritis reumatoide ${ }^{(33)}$. Con respecto al COVID-19, este fármaco actúa al inhibir la tormenta de citocinas que se inicia en la fase inicial, al bloquear a la interleucina - 6, evitando así el inicio del SDRA. Además se ha encontrado relacionado el aumento de esta interleucina con el aumento de la mortalidad en los pacientes con COVID-19 ${ }^{(34)}$. Se considera un tratamiento seguro para adultos y niños a partir de dos años, además el efecto adverso grave que más se ha reportado es la presencia de infecciones en pacientes con tratamiento crónico ${ }^{(35)}$. Otros efectos adversos que pueden presentarse con menor frecuencia en el tratamiento con tocilizumab son perforaciones gastrointestinales, reacciones a la infusión, anafilaxia y alteraciones en el perfil laboratorial, además no se recomienda su usa en gestantes debido a que atraviesa la barrera placentaria ${ }^{(36)}$. Con respecto a la interacción con otras drogas el Tocilizumab no afecta directamente al citocromo, pero al actuar sobre la IL-6 puede aumentar la presencia de algunos citocromos que fueron deprimidos al elevarse la interleucina, lo que puede afectar el metabolismo de algunos fármacos. Se debe tener cuidado con los fármacos mielotóxicos debido a que potencia su toxicidad hematológica ${ }^{(37)}$. La dosis habitual usada en el tratamiento de la tormenta de citocinas es de una infusión lenta por vía intravenosa de $8 \mathrm{mg} / \mathrm{kg}$ en pacientes $>30 \mathrm{~kg}$ o de $12 \mathrm{mg} / \mathrm{kg}$ en pacientes < $30 \mathrm{~kg}$, y en caso haya mala respuesta se administran dos dosis más con un intervalo de 8 horas entre cada una de ellas ${ }^{(38)}$.

En un hospital en Lombardía, Italia se realizó un estudio de casos en 100 pacientes con SARS-CoV-2 confirmado por PCR quienes además presentaron insuficiencia respiratoria aguda con necesidad de soporte ventilatorio, pero no todos se encontraban en ventilación mecánica debido a la falta de disponibilidad, los cuales fueron tratadas con Tocilizumab a una dosis de $8 \mathrm{mg} / \mathrm{kg}$ vía infusión intravenosa cada 12 horas, recibiendo en total de 2 a 3 infusiones. El 77\% de los pacientes tuvieron una notable mejoría evidenciada dentro de las primeras 24 horas y completa hasta el décimo día pudiendo suspender la ventilación mecánica e incluso algunos hasta ser dados de alta, del resto de los pacientes el $23 \%$ empeoró y de ellos el $20 \%$ falleció $^{(39)}$. En otro hospital de Italia se reportó el caso de un paciente de 50 años con COVID-19 quien recibió tratamiento combinado con hidroxicloroquina, azitromicina y baricitinib sin presentar mejoría por lo que se adiciono esteroides con tocilizumab a una dosis IV de $8 \mathrm{mg} / \mathrm{kg}$, presentando mejoría luego de 4 días de administración de este último, y finalmente con remdesivir manteniendo el uso de hidroxicloroquina y esteroides, presentando recuperación tanto radiológica como clínica ${ }^{(40)}$.

En Baréin se reportó el caso de 5 pacientes con COVID - 19 tratados con tocilizumab recibiendo de una a dos dosis de 400 mg vía intravenosa según requerimiento, de los cuales 4 presentaron mejoría clínica a partir de las 24 horas del tratamiento y fueron dado de alta de $\mathrm{UCl}$ estando hemodinámicamente estable, pero 1 paciente falleció debido a shock refractario asociado a hipoxemia refractaria e insuficiencia circulatoria ${ }^{(41)}$. En Turquía se realizó un estudio de casos retrospectivo que evaluó la eficacia de tocilizumab en 43 pacientes con COVID - 19 severo ( 21 pacientes) o crítico (22 pacientes) a los cuales se les hizo seguimiento por 14 días posterior al inicio del tratamiento de tocilizumab, los cuales iniciaron con el tratamiento estándar y debido a la sospecha de tormenta de citocinas se les administró $8 \mathrm{mg} / \mathrm{kg}$ de tocilizumab como dosis inicial, en algunos casos fue necesario administrar una segunda dosis luego de 12 horas de haber aplicado la primera; 3 pacientes con COVID - 19 severo tuvieron que ser hospitalizados en $\mathrm{UCl}$, pero todos presentaron mejoría radiológica al séptimo día, 9 pacientes con COVID - 19 crítico presentaron infecciones bacterianas secundarias y 6 pacientes fallecieron ${ }^{(42)}$. En otro lugar de Italia, se realizó un estudio de casos y controles retrospectivo a 128 pacientes en total, 64 pacientes por cada grupo, siendo uno de ellos los que recibieron tratamiento con tocilizumab también por infusión intravenosa a una dosis de $8 \mathrm{mg} / \mathrm{kg}$, esos pacientes presentaron menor riesgo de necesidad de soporte ventilatorio de apoyo, pero la mortalidad fue similar en ambos casos, presentando una tasa similar en la supervivencia dentro de los primeros 30 días $^{(43)}$.

En Francia se llevó a cabo un estudio retrospectivo de casos y controles que incluyó a 20 pacientes que recibieron tocilizumab y a 25 que recibieron tratamiento estándar, encontrándose que a pesar que los pacientes tratados con tocilizumab tenían mayor demanda de oxígeno y peores resultados de laboratorio, a pesar de esto el ingreso a $\mathrm{UCl}$ y las muertes fueron mayores en los pacientes que recibieron tratamiento estándar teniendo a un $72 \%$ frente a un $25 \%$ respectivamente, así mismo los pacientes con tratamiento estándar necesitaron en un mayor porcentaje la ventilación mecánica invasiva en comparación con el grupo que recibió tocilizumab teniendo a un $32 \%$ para el primer grupo y $0 \%$ para el segundo grupo ${ }^{(44)}$. En Francia también se realizó un estudio retrospectivo de casos y controles con 206 pacientes, de los cuales 30 recibieron tocilizumab y 176 recibieron tratamiento estándar, en el seguimiento se encontró que los pacientes con tocilizumab tuvieron una menor mortalidad y menor necesidad de ventilación mecánica las cuales estuvieron en un $27 \%$ en comparación con el $52 \%$ del otro grupo $^{(45)}$. 
Revista del Cuerpo Médico del HNAAA, Vol 14 (1) - 2021

Un estudio de cohorte retrospectivo se llevó a cabo en Italia donde se evalúo a los pacientes que ingresaron con COVID - 19 grave o crítico y que fueron tratados con tocilizumab en infusión por 60 minutos a una dosis de $8 \mathrm{mg} / \mathrm{kg}$ siendo un total de 74 pacientes, comparándolos con 148 pacientes que recibieron otro tratamiento, encontrándose que los pacientes que recibieron tratamiento con tocilizumab tuvieron un mayor porcentaje de mejoría de su estado $(62 \%$ de los pacientes), especialmente en los pacientes con ventilación mecánica, pero tuvieron una mayor estancia hospitalaria en comparación con el otro grupo ${ }^{(46)}$. En otra región de Italia, se realizó un estudio de cohorte retrospectivo, teniendo a 544 pacientes con COVID-19 severo, de los cuales 365 recibieron tratamiento estándar y 179 recibieron tratamiento con tocilizumab por vía intravenosa o subcutánea, encontrándose que los pacientes tratados con tocilizumab presentaron menor riesgo de necesidad de ventilación mecánica o de muerte en comparación con el otro grupo, pero el grupo tratado con tocilizumab presento un mayor porcentaje de pacientes con nuevas infecciones asociadas al tratamiento ${ }^{(47)}$. En Italia también se llevó a cabo un estudio de cohorte retrospectivo que incluyó a 158 pacientes, de los cuales 90 pacientes recibieron tocilizumab (43 pacientes recibieron $400 \mathrm{mg}$ de tocilizumab intravenoso y 47 pacientes recibieron $324 \mathrm{mg}$ de tocilizumab subcutáneo) y 68 pacientes recibieron tratamiento estándar, de los pacientes que recibieron tocilizumab falleció el 7,7\%, mientras que de los pacientes que recibieron el tratamiento estándar falleció el 50\%, encontrándose que tocilizumab mejoró la supervivencia en su grupo de pacientes, además no se encontró relacionado con reacciones adversas ni se encontró diferencias con respecto a la vía de administración ${ }^{(48)}$. En otro lugar en Italia se llevó a cabo un estudio de cohorte retrospectivo que incluyó a 65 pacientes con COVID - 19, de los cuales 32 pacientes recibieron de una a dos dosis de $400 \mathrm{mg}$ de tocilizumab intravenoso además del tratamiento estándar y los demás pacientes solo recibieron tratamiento estándar, en el día 28 se realizó un seguimiento encontrándose que el $69 \%$ de los pacientes con tocilizumab presentó mejoría clínica mientras que del grupo estándar solo el $61 \%$, la mortalidad fue del $15 \%$ y del $33 \%$ para cada grupo respectivamente, teniendo como predictor de mortalidad a la edad avanzada y como predictor de mejoría una $\mathrm{PaO2}$ :FiO2 basal elevada, mientras que la comparación de infecciones secundarias fue similar en ambos grupos estando en $13 \%{ }^{(49)}$. Otro estudio similar de cohorte retrospectivo se llevó en Estados Unidos, en donde se observó a 630 pacientes con COVID - 19 que requerían atención en cuidados intensivos, de ellos solo 21 recibieron tratamiento con tocilizumab, encontrando también que los pacientes tratados con tocilizumab presentaron un menor riesgo de mortalidad en comparación con el otro grupo, pero superaron la media esperada de estancia hospitalaria llegando hasta 23 días $^{(50)}$.

En Estados Unidos también se realizó un estudio de cohorte retrospectivo en 52 pacientes hospitalizados con COVID-19, quienes se les administró de 1 a 4 dosis de tocilizumab luego de 14 días de iniciados los síntomas, de ellos solo el $42.3 \%$ de pacientes respondió favorablemente al tratamiento y $46.2 \%$ fallecieron ${ }^{(51)}$. Mientras que en España se llevó a cabo un estudio de cohorte con 1229 pacientes, 261 pacientes recibieron tocilizumab y 969 pacientes recibieron el tratamiento estándar, encontrando que el tocilizumab se asoció a una disminución del riesgo de muerte o de ingreso a $\mathrm{UCl}$ en los pacientes que tenían una proteína $C$ reactiva basal mayor a $150 \mathrm{mg} / \mathrm{L}$; sin embargo, en los pacientes que tuvieron menores niveles de proteína $C$ reactiva el efecto fue similar que el del grupo que recibió tratamiento estándar ${ }^{(52)}$. A diferencia de otro estudio realizado en Italia de tipo cohorte observacional donde se evaluó a 12 pacientes con COVID-19 que recibieron de una a dos dosis de $162 \mathrm{mg}$ de tocilizumab subcutáneo, observándose que luego de la administración de tocilizumab disminuyó el valor de los marcadores inflamatorios sanguíneos, además hubo mejoría de la función respiratoria, disminuyendo las respiraciones por minuto a menos de 30 , obteniendo una saturación de oxígeno mayor a 93 y un PaO2FiO2 mayor a 300; por otro lado, se realizó un seguimiento tomográfico en el cuál se observó mejoría en todos los pacientes y no se informaron efectos adversos o problemas de seguridad por el tratamiento con tocilizumab ${ }^{(53)}$.

En Estados Unidos se llevó a cabo un estudio cohorte retrospectivo comparando el uso de tocilizumab intravenoso con el subcutáneo, para lo cual incluyeron a 125 pacientes, de los cuales 65 recibieron $400 \mathrm{mg}$ de tocilizumab intravenoso y 60 recibieron $324 \mathrm{mg}$ de tocilizumab subcutáneo. En el seguimiento se obtuvo que el $52 \%$ y el $28 \%$ de los pacientes respectivamente para cada grupo presentaron mejoría clínica dentro de los primeros 7 días, la tasa de mortalidad fue del $37 \%$ y del $50 \%$ respectivamente, y con respecto a los marcadores inflamatorios se observó un descenso de la proteína $C$ reactiva ${ }^{(54)}$. En Irán se llevó a cabo un ensayo clínico prospectivo no controlado, evaluando a 42 pacientes con COVID - 19 crítico o severo a los cuales se les administró una dosis de $400 \mathrm{mg}$ de tocilizumab vía intravenosa, de los cuales el $14 \%$ requirió ventilación mecánica invasiva, mientras que el $83,33 \%$ presentó mejoría clínica, luego de 28 días de iniciado el tratamiento falleció el $16,66 \%$ y el 7,14\% presentó reacciones adversas neurológicas como la diplopía transitoria y la parálisis de Bell ${ }^{(55)}$. Por otro lado, en Italia se llevó a cabo un ensayo multicéntrico prospectivo, abierto y no controlado, donde se incluyó a 126 pacientes con COVID 19 donde 86 pacientes tenían COVID - 19 grave y 40 pacientes con COVID - 19 crítico, quienes recibieron una dosis de $324 \mathrm{mg}$ de tocilizumab subcutáneo para los que pesaban menos de $100 \mathrm{~kg}$ y $486 \mathrm{mg}$ para los que pesaban más de $100 \mathrm{~kg}$, además del tratamiento estándar. El seguimiento se realizó hasta el alta o fallecimiento de los pacientes, encontrándose que la duración media de estancia hospitalaria fue de 8 días, el $76.19 \%$ del total de los pacientes sobrevivió y fue dado de alta del hospital, mientras que los fallecidos fueron el 6,98\% de los pacientes graves y el $60 \%$ de los pacientes críticos, con respecto a la necesidad de oxígeno complementario este disminuyó más en los pacientes graves que en los pacientes críticos, la frecuencia respiratoria disminuyó en ambos grupos, así como la temperatura corporal, mientras que la saturación de oxígeno aumentó significativamente en ambos grupos; finalmente, no se presentaron efectos adversos graves asociados al uso de tocilizumab ${ }^{(56)}$.

En Italia también se llevó a cabo un ensayo prospectivo multicéntrico, para estudiar el efecto del tocilizumab sobre la tasa de letalidad en los días 14 y 30, teniendo a 301 pacientes con COVID - 19, de los cuales 180 recibieron 8 
Revista del Cuerpo Médico del HNAAA, Vol 14 (1) - 2021

$\mathrm{mg} / \mathrm{kg}$ de tocilizumab con una dosis máxima de $800 \mathrm{mg}$ por dosis, si la función respiratoria no mejoraba se aplicaba una segunda dosis 12 horas después. En los resultados se encontró que la tasa de letalidad fue de $18,4 \%$ para el día 14 y de $22,4 \%$ para el día 30 , además no se encontró en ningún paciente toxicidad farmacológica, además se encontró que el tratamiento con tocilizumab es más efectivo en pacientes que no requieren soporte ventilatorio ${ }^{(57)}$.

\section{ANAKINRA}

El anakinra es un fármaco recombinante del antagonista del receptor humano para la interleucina 1 (IL-1RA), usado principalmente en pacientes con artritis reumatoide ${ }^{(9)}$, puede inhibir tanto a la IL-1a como a la IL-1b ambas asociadas con la inmunidad innata ${ }^{(58)}$. Estas interleucina se han visto relacionadas con el SDRA causada por la tormenta de citocinas y la linfohistiocitosis hemofagocítica, la cual se ha visto presente en el COVID-19 y puede ser controlada por anakinra siendo eficaz en horas y presentando una vida media corta, lo que lo convierte en un fármaco de uso seguro, ya que si presentará algún efecto secundario se detendrá prontamente, lo que le da un adecuado perfil de seguridad ${ }^{(59)}$. Esto ocurre cuando el COVID-19 al causar daño epitelial produce la liberación de la IL-1a, que a su vez realizará el reclutamiento de neutrófilos y monocitos al sitio afectado, además inducirá a la IL-1b tanto en monocitos como en macrófagos; por otro lado, el COVID-19 también libera un pro-IL1b que actúa en las células previamente mencionadas, lo que culmina en mayor liberación de IL-1 y posterior activación de células inmunes innatas, llevando a un proceso continuo y sin regulación. El anakinra al bloquear ambas interleucinas evita este proceso, además disminuye la producción de la IL-6 debido a que la IL-1 es uno de sus inductores ${ }^{(60)}$

Anakinra se puede utilizar por la vía intravenosa y la vía subcutánea, pero la vía más recomendada es la subcutánea debido a que mantiene una biodisponibilidad adecuada del fármaco. Además, tiene una vida de media corta, lo que permite actuar prontamente en caso se presenten efectos adversos $^{(61)}$.

En Canadá se reportó el caso de una paciente de 62 años con COVID-19 y miocarditis fulminante, con antecedente de esclerosis múltiple progresiva, quien fue tratado con anakinra a dosis de $100 \mathrm{mg}$ cada 12 horas por vía intravenosa, presentando mejoría clínica evidente dentro de las primeras 72 horas de tratamiento, por lo que se le continuó por los siguientes 5 días, el paciente fue dado de alta dos semanas después teniendo resolución del problema cardíaco y pulmonar $^{(62)}$. De la misma manera en Italia se reporta el caso de un paciente de 50 años con COVID-19 a quien se le inició anakinra en su décimo día de ingreso debido a su estado crítico y a presentar contraindicación para el uso de tocilizumab, la dosis inicial fue de $200 \mathrm{mg}$ por vía intravenosa, seguida de $100 \mathrm{mg}$ cada 6 horas por vía subcutánea, este tratamiento se continuó hasta el día 21 de su ingreso, fue dado de alta de $\mathrm{UCl}$ presentando mejoría clínica, pero se le tuvo que retirar el tratamiento con anakinra debido a una bacteriemia asociada al catéter venoso central, luego del tratamiento antibiótico fue dado de alta a los 29 días de ingreso en buen estado general ${ }^{(63)}$. Así como en Reino Unido, se presenta el caso de un paciente de 17 años con COVID - 19 asociado a linfohistiocitosis hemofagocítica secundaria, a quien se le administró anakinra $100 \mathrm{mg}$ por día vía intravenosa en su segundo día de hospitalizado, presentando mejoría dentro de las siguientes 24 horas, el tratamiento se suspendió en el noveno día y el paciente fue dado de alta en el décimo primer día posterior a su ingreso ${ }^{(64)}$.

En un estudio realizado en Grecia y en los Países Bajos se reportan los casos de 8 pacientes con COVID - 19 severo con linfohistiocitosis hemofagocítica secundaria que fueron tratados con $200 \mathrm{mg}$ de anakinra intravenosa cada 8 horas por 6 días, presentando mejoría de la afección pulmonar y menor necesidad de uso de Vasopresores; sin embargo, 3 pacientes fallecieron por shock séptico refractario a parte del noveno día posterior al inicio del tratamiento ${ }^{(65)}$. De la misma manera, en otro hospital en España se reporta un caso de un paciente de 51 años con COVID - 19 con necesidad de ventilación mecánica, quien no presento mejoría al tratamiento con tocilizumab, por lo que dos días después de haber recibido tocilizumab inició el tratamiento con anakinra vía subcutánea a dosis única de $100 \mathrm{mg}$, presentando luego una respuesta favorable con adecuada evolución clínica, siendo retirado del soporte ventilatorio y dado de alta a los 14 días de haber ingresado ${ }^{(66)}$.

En otra región de Italia se realizó un estudio de cohorte retrospectivo a pacientes con COVID - 19 moderado o severo asociado a hiperinflamación, de ellos 29 pacientes recibieron tratamiento con anakinra pudiendo ser por vía intravenosa a dosis de $5 \mathrm{mg} / \mathrm{kg}$ o por vía subcutánea a dosis de $100 \mathrm{mg}$ dos veces al día, comparándolos con 16 pacientes que recibieron el tratamiento estándar, encontrando como resultado a los 21 días de iniciado el tratamiento que los pacientes tratados con anakinra presentaron un mayor porcentaje de supervivencia, presentando además un elevado porcentaje de supervivencia sin ventilación invasiva, pero un mayor porcentaje de pacientes tratados con anakinra presentó bacteriemia; sin embargo, luego de la suspensión de anakinra no presentaron recaídas inflamatorias ${ }^{(67)}$. Mientras que en Estados Unidos se realizó un estudio de cohorte retrospectivo en 41 pacientes hospitalizados con COVID-19, quienes recibieron anakinra por 9 días, luego de 14 días de iniciados los síntomas, de ellos solo el $63,4 \%$ respondieron favorablemente al tratamiento, con un $22 \%$ de pacientes fallecidos ${ }^{(51)}$.

En Francia se realizaron dos estudios de tipo cohorte prospectivo con 52 pacientes y de cohorte retrospectivo con 44 pacientes, los pacientes que recibieron el tratamiento de anakinra lo hicieron vía subcutánea a dosis de $100 \mathrm{mg}$ cada 12 horas por 72 horas y luego cada 24 horas por 7 días, el otro grupo tratamiento estándar, los resultados del estudio arrojaron que el grupo de anakinra tuvo menos pacientes fallecidos o ingresados a UCI (25\%) en comparación con el otro grupo (73\%), además el grupo de pacientes tratados con anakinra que sobrevivió disminuyó progresivamente la necesidad de oxígeno suplementario, ninguno presentó otras infecciones intrahospitalarias y solo el 13\% presentó elevación de las enzimas hepáticas ${ }^{(68)}$. De la misma manera en un hospital en España se realizó un estudio de cohorte retrospectivo a pacientes con COVID - 19 y SDRA, de los cuáles 9 recibieron tratamiento con anakinra subcutánea a dosis de 
Revista del Cuerpo Médico del HNAAA, Vol 14 (1) - 2021

100 mg cada 6 horas y el otro grupo se encontró compuesto por 18 pacientes que recibieron tratamiento con tocilizumab, los resultados fueron favorables para ambos grupos, presentando mejoría clínica en el $55,6 \%$ y el $88,9 \%$ de los pacientes respectivamente, además no se presentaron infecciones oportunistas, y se vieron los casos de 2 pacientes que presentaron resistencia al tratamiento con tocilizumab que mejoraron cuando empezaron a recibir anakinra, la elevación de aminotransferasas se vio solo en el grupo de tocilizumab, ambos presentaron una mortalidad del $11 \%$ y ninguna reacción adversa ${ }^{(69)}$.

\section{BARICITINIB}

El baricitinib es un agente biológico inhibidor de la Janus quinasa (JAK), selectivamente al JAK1/JAK2 bloqueando de esta manera la vía de señalización del JAK que usa el SARSCOV-2 y las citocinas dependientes de esta vía como son la IL6, IL-2, IL-23 e IFN -y para evitar la tormenta de citocinas. Esta vía inicia con la angiotensina II tipo 1 (AT1-R), quien es secretada en exceso luego de la unión del virus a la enzima convertidora de angiotensina II (ACE-2), la AT1-R actúa a través del transductor de señal Janus quinasa y a través de la vía de señalización del activador de la transcripción (JAKSTAT), provocando mediante ellos vasoconstricción, hipertensión y daño tisular crónico; pudiendo afectar en el sistema cardiovascular, en las células tubulares proximales renales, en las células mesangiales, en los astrocitos del tronco encefálico y en los hepatocitos ${ }^{(70)}$.

Además, el baricitinib también interfiere en el paso y ensamblaje del virus en las células pulmonares, debido a que interrumpe la señalización de proteína-quinasa- 1 asociada a AP2 (AKK1) y de la quinasa asociada a ciclina G (GAK), las cuales son reguladores que median la endocitosis dependiente de clatrina. Este mecanismo ayudaría a disminuir la entrada viral del SARS-COV-2, lo que es sugerido para iniciar el tratamiento con el fármaco. Sin embargo, el mecanismo previo referido se encontraría más recomendado para fases moderadas o severas de la enfermedad ya que es ahí donde se presenta la tormenta de citocinas, a diferencia de los casos leves o asintomáticos donde es muy probable que el virus sea eliminado por mecanismos antivirales endógenos ${ }^{(71)}$.

La concentración plasmática de baricitinib necesaria para lograr este efecto se consigue con la dosis terapéutica de 20 $4 \mathrm{mg}$ por vía oral una vez al día. Sin embargo, puede afectar la respuesta del interferón (IFN) alfa y beta al bloquear la vía de señalización lo que podría empeorar la infección, debido a que una disminución de respuesta del IFN puede causar un exceso en la replicación viral, pero también disminuir el riesgo de enfermedad pulmonar grave al evitar la regulación negativa $^{(72)}$.

Los efectos del baricitinib han sido comprobados in vitro, además de su disponibilidad de administración por vía oral, de su perfil aceptable de efectos secundarios y debido a su poca interacción con las enzimas CYP y los transportadores de fármacos. Lo que lo hace apropiado para usarlo tanto en las primeras etapas de la infección para poder reducir la entrada viral en las células como en las posteriores para hacer uso de sus efectos antiinflamatorios ${ }^{(73)}$. Es necesario mantener una adecuada vigilancia del uso del baricitinib si es que se usa con inmunosupresores debido a que se ha encontrado casos de aparición de enfermedades oportunistas al hacer uso de $\operatorname{estos}^{(74)}$.

En Alemania, se reporta el caso de un paciente de 71 años con falla respiratoria por COVID - 19, quien recibió tratamiento estándar seguido de 3 días de tratamiento con sarilumab, a quien debido a la falta de respuesta se le inicia tratamiento con $4 \mathrm{mg}$ de baricitinib vía oral por 2 semanas, presentando mejoría clínica y radiológica después de terminado el tratamiento ${ }^{(75)}$. En Estados Unidos, se realizó un estudio de cohorte retrospectivo con 15 pacientes con COVID -19 moderado o severo, quienes recibieron tratamiento combinado de 200 a $400 \mathrm{mg}$ de hidroxicloroquina con 2 a $4 \mathrm{mg}$ de baricitinib vía oral. En los resultados se observó que el $60 \%$ ingresó a $\mathrm{UCl}$ y el $26,7 \%$ requirió ventilación mecánica, pero desde el inicio del tratamiento con baricitinib se evidenció mejoría en los síntomas, presentando un menor requerimiento del soporte de oxígeno, además dando una disminución de los valores de PCR, en total se evidenció una supervivencia del $80 \%^{(76)}$.

En Italia se llevó a cabo un ensayo clínico no aleatorizado con 24 pacientes con COVID - 19 a quienes se les hizo seguimiento por 2 semanas, de ellos a 12 se les administró $4 \mathrm{mg}$ de baricitinib por día con 200/50 mg de lopinavir/ritonavir dos veces al día durante dos semanas, siendo los controles los 12 pacientes previos que habían recibido tratamiento estándar. Presentando una notable diferencia en ambos grupos, el grupo control tuvo $33 \%$ de ingreso a $\mathrm{UCl}$, mientras que el otro grupo no tuvo ningún ingreso, además el alta en el grupo control luego de 2 semanas fue del $8 \%$, mientras que en el otro grupo fue de $58 \%$, esto se asoció a una mejoría clínica, disminución de la necesidad de oxígeno suplementario y de valores inflamatorios en los exámenes de laboratorio, pero como efecto adverso se presentaron alteraciones cardiovasculares y hematológicas ${ }^{(77)}$. Además, la Administración de Alimentos y Medicamentos de los Estados Unidos o FDA ha dado una autorización de emergencia para el inicio del uso del baricitinib en acompañamiento con remdesivir para el tratamiento de adultos y niños mayores de 2 años con COVID - 19, especialmente en los casos donde haya la necesidad de oxígeno suplementario, basándose en los resultados favorables de un ensayo clínico aleatorizado, doble ciego y controlado con placebo que incluyó a 1033 pacientes con COVID - 19 a quienes se les realizó seguimiento por 29 días, de ellos 515 pacientes recibieron tratamiento con baricitinib y remdesivir, mientras que 518 pacientes recibieron placebo y remdesivir, presentando el grupo con baricitinib menor tiempo medio de recuperación, menor probabilidad de ventilación mecánica y de muerte en comparación con el grupo control ${ }^{(78)}$.

\section{CONCLUSIONES}

Según lo revisado en este artículo, encontramos que el tratamiento con hidroxicloroquina en los primeros ensayos de tipo cohorte retrospectivo que se realizaron presentaron resultados favorables comparables con lo presenta la teoría, disminuyendo el riesgo de mortalidad y el riesgo de ingreso a $\mathrm{UCl}$, además en uno de los estudios también se evidenció disminución de la carga viral. Sin embargo, en los estudios de 
tipo ensayo clínico aleatorizado no se evidenció beneficio del tratamiento de la hidroxicloroquina sobre el tratamiento estándar presentado similar riesgo de mortalidad, riesgo de necesidad de ventilación mecánica y similar disminución de la carga viral; lo que se asemeja con los diferentes estudios actuales relacionados al tratamiento de hidroxicloroquina para el COVID - 19. Por otro lado, los principales efectos adversos que se presentaron en los diferentes estudios fueron los gastrointestinales, no encontrándose presencia de cambios electrocardiográficos significativos en ninguno de ellos. Además, en el estudio realizado en pacientes ambulatorios no se encontró diferencias en la gravedad de los síntomas ni en la tasa de mortalidad, pero si hubo menor riesgo de hospitalización en los pacientes tratados con hidroxicloroquina.

Al revisar el uso del tratamiento con tocilizumab, los casos presentados mostraron en su mayoría una mejoría notable luego de iniciado el tratamiento, de la misma manera en casi todos los estudios de tipo cohorte retrospectivo se evidenció una mejoría clínica y/o radiológica con disminución del riesgo de mortalidad luego de recibir el tratamiento tanto en pacientes en unidad de cuidados críticos como fuera de esta, sin mostrar diferencia con la vía administrada, solo en un estudio de este tipo aumentó la tasa de mortalidad luego del tratamiento. De la misma manera en los estudios de tipo cohorte retrospectivo se asoció el tratamiento con tocilizumab a una disminución del riesgo de la mortalidad o de ingreso a cuidados críticos y a un aumento de la mejoría clínica - radiológica, presentando mayor eficacia el tratamiento intravenoso, así mismo en la mayoría de los estudios de tipo casos y controles retrospectivos se encontraron similares resultados, pero solo en uno se encontró que el riesgo de mortalidad fue el mismo. Finalmente, en los ensayos multicéntricos prospectivos no controlados se encontró de igual manera que luego del tratamiento con tocilizumab los pacientes presentaron mejoría clínica y radiológica, especialmente en los que presentaron aumento de marcadores inflamatorios, con disminución del riesgo de mortalidad; sin embargo, sería necesario comparar los resultados con ensayos clínicos aleatorizados, los cuales no se encontraron en las bases de datos. De manera general en los estudios se encontró como principal efecto adverso a la infección secundaria, lo que se sumó al aumento de días de hospitalización.

La evidencia del tratamiento con anakinra en la mayoría de los casos presentados se observó una mejoría clínica evidente en los pacientes, especialmente en aquellos que presentaron resistencia al tratamiento con tocilizumab, por lo que podría ser una alternativa de tratamiento para estos casos o en los que casos que el tratamiento con tocilizumab se encuentra contraindicado. De la misma manera en los estudios de tipo cohorte retrospectivo, se presentó una mejoría clínica evidenciada principalmente por la disminución de la necesidad de oxígeno suplementario, asociada a una disminución de la tasa de mortalidad y del riesgo de soporte ventilatorio; sin embargo, se deberían comparar los resultados obtenidos con ensayos clínicos aleatorizados, estos tampoco se encontraron en las bases de datos. El efecto adverso más frecuente mencionado en los estudios es la bacteriemia secundaria que resolvió sin presentar trastornos de gravedad.
En el caso de baricitinib se encontraron los mismos resultados satisfactorios tanto en los casos reportados, como en los estudios de cohorte y en los ensayos clínicos, presentando una disminución de la mortalidad, un menor riesgo de soporte ventilatorio, y una mejoría clínica evidente en los pacientes. Sin embargo, los estudios fueron realizados en adición con otros fármacos, por lo que sería necesario evaluar la eficacia solo del fármaco sin otro en combinación. Mientras que los efectos adversos que se reportaron fueron las alteraciones cardiovasculares y hematológicas.

Como se ha podido observar el tratamiento con hidroxicloroquina para el COVID - 19 fue descalificado luego de realizar estudios de mayor nivel. Por lo que, tanto el tratamiento con tocilizumab como el tratamiento con anakinra que presentan adecuados resultados en estos primeros estudios deberían ser evaluados en estudios de mayor nivel para confirmar su eficacia en la enfermedad. Mientras que el tratamiento con baricitinib ha presentado resultados favorables en los diferentes trabajos presentados, siendo el único antirreumático autorizado por la FDA hasta el momento; sin embargo, es necesario continuar haciendo investigaciones sobre el tratamiento único con este fármaco para asegurar nuevos tratamientos en el COVID - 19 y poder afrontar la pandemia en la que estamos viviendo.

\section{REFERENCIAS BIBLIOGRÁFICAS}

1. Shereen MA, Khan S, Kazmi A, Bashir N, Siddique R. COVID-19 infection: Origin, transmission, and characteristics of human coronaviruses. JAdv Res. julio de 2020;24:91-8.

2. Jin Y, Yang H, Ji W, Wu W, Chen S, Zhang W, et al. Virology, Epidemiology, Pathogenesis, and Control of COVID-19. Viruses. 27 de 2020;12(4)

3. Tian W, Jiang W, Yao J, Nicholson CJ, Li RH, Sigurslid HH, et al. Predictors of mortality in hospitalized COVID-19 patients: A systematic review and meta-analysis. J Med Virol. 22 de mayo de 2020;

4. Brito AE. COVID-19: rápida revisión general. Anales de la Academia de Ciencias de Cuba [Internet]. 29 de abril de 2020 [citado 20 de junio de 2020];10(2):828. Disponible en: http://revistaccuba.sld.cu/index.php/revacc/article/view/8 28

5. Rothan HA, Byrareddy SN. The epidemiology and pathogenesis of coronavirus disease (COVID-19) outbreak. J Autoimmun. 2020;109:102433.

6. Camba AR, Muñoz RM. SÍNDROME DE ACTIVACIÓN DEL MACRÓFAGO. :8.

7. Misra DP, Agarwal V, Gasparyan AY, Zimba O. Rheumatologists' perspective on coronavirus disease 19 (COVID-19) and potential therapeutic targets. Clin Rheumatol. 10 de abril de 2020;

8. Danza Á, Graña D, Goñi M, Vargas A, Ruiz-Irastorza G. Hidroxicloroquina en el tratamiento de las enfermedades autoinmunes sistémicas. Revista médica de Chile [Internet]. febrero de 2016 [citado 20 de junio de 2020];144(2):232-40. D i s p o n i b l e e $n$ : https: //scielo.conicyt.cl/scielo.php?script=sci abstract\&pid $=$ S0034-98872016000200012\&lng=es\&nrm=iso\&tlng=es

9. Wu R, Wang L, Kuo H-CD, Shannar A, Peter R, Chou PJ, et al. An Update on Current Therapeutic Drugs Treating COVID-19. Curr Pharmacol Rep. 11 de mayo de 2020;1-15.

10. Picchianti Diamanti $A$, Rosado $M M$, Pioli $C$, Sesti G, Laganà B. Cytokine Release Syndrome in COVID-19 Patients, A New Scenario for an Old Concern: The Fragile Balance between Infections and Autoimmunity. Int J Mol Sci. 8 de mayo de 2020;21(9) 
11. Ye Q, Wang $B$, Mao J. The pathogenesis and treatment of the 'Cytokine Storm' in COVID-19. J Infect. 2020;80(6):607-13.

12. Acosta G, Escobar G, Bernaola G, Alfaro J, Taype W, Marcos C, et al. Caracterización de pacientes con COVID-19 grave atendidos en un hospital de referencia nacional del Perú. Revista Peruana de Medicina Experimental y Salud Pública [Internet]. 21 de abril de 2020 [citado 13 de junio de $20200 ; 37(2)$. D is ponible e n : https://rpmesp.ins.gob.pe/index.php/rpmesp/article/view/ 5437

13. Sun P, Lu X, Xu C, Sun W, Pan B. Understanding of COVID-19 based on current evidence. J Med Virol. 25 de febrero de 2020;

14. Choudhary R, Sharma AK. Potential use of hydroxychloroquine, ivermectin and azithromycin drugs in fighting COVID-19: trends, scope and relevance. New Microbes New Infect. mayo de 2020;35:100684.

15. Ibáñez S, Martínez 0 , Valenzuela F, Silva F, Valenzuela 0 . Hydroxychloroquine and chloroquine in COVID-19: should they be used as standard therapy? Clin Rheumatol. agosto de 2020;39(8):2461-5.

16. Shukla AM, Archibald LK, Wagle Shukla A, Mehta HJ, Cherabuddi $\mathrm{K}$. Chloroquine and hydroxychloroquine in the context of COVID-19. Drugs Context. 2020;9.

17. Hashem AM, Alghamdi BS, Algaissi AA, Alshehri FS, Bukhari A, Alfaleh MA, et al. Therapeutic use of chloroquine and hydroxychloroquine in COVID-19 and other viral infections: A narrative review. Travel Med Infect Dis. junio de 2020;35:101735.

18. Sun J, Chen Y, Fan X, Wang X, Han Q, Liu Z. Advances in the use of chloroquine and hydroxychloroquine for the treatment of COVID-19. Postgrad Med. septiembre de 2020;132(7):604-13.

19. Zou L, Dai L, Zhang X, Zhang Z, Zhang Z. Hydroxychloroquine and chloroquine: a potential and controversial treatment for COVID-19. Arch Pharm Res. agosto de 2020;43(8):765-72.

20. Arshad S, Kilgore P, Chaudhry ZS, Jacobsen G, Wang DD, Huitsing $\mathrm{K}$, et al. Treatment with hydroxychloroquine, azithromycin, and combination in patients hospitalized with COVID-19. International Journal of Infectious Diseases [Internet]. 1 de agosto de 2020 [citado 31 de octubre de 2020 ]; $97: 396-403$. Disponible en: http://www.sciencedirect.com/science/article/pii/S120197 1220305348

21. Lammers AJJ, Brohet RM, Theunissen REP, Koster C, Rood R, Verhagen DWM, et al. Early Hydroxychloroquine but not Chloroquine use reduces ICU admission in COVID-19 patients. International Journal of Infectious Diseases [Internet]. 29 de septiembre de 2020 [citado 4 de noviembre de 2020]; D i s p o n i ble

e $\mathrm{n}$ : http://www.sciencedirect.com/science/article/pii/S120197 1220321755

22. Almazrou SH, Almalki ZS, Alanazi AS, Alqahtani AM, Alghamd SM. Comparing the impact of Hydroxychloroquine based regimens and standard treatment on COVID-19 patient outcomes: A retrospective cohort study. Saudi Pharmaceutical Journal [Internet]. 1 de octubre de 2020 [citado 5 de noviembre de 2020 ]; Disponible en: http://www.sciencedirect.com/science/article/pii/S131901 6420302334

23. Castelnuovo AD, Costanzo S, Antinori A, Berselli N, Blandi L, Bruno $\mathrm{R}$, et al. Use of hydroxychloroquine in hospitalised COVID-19 patients is associated with reduced mortality: Findings from the observational multicentre Italian CORIST study. European Journal of Internal Medicine [Internet]. 25 de agosto de 2020 [citado 5 de noviembre de 2020]; Disponible en: http://www.sciencedirect.com/science/article/pii/S095362 0520303356

24. Catteau L, Dauby N, Montourcy M, Bottieau E, Hautekiet J, Goetghebeur E, et al. Low-dose hydroxychloroquine therapy and mortality in hospitalised patients with COVID-19: a nationwide observational study of 8075 participants. International Journal of Antimicrobial Agents [Internet]. 1 de octubre de 2020 [citado 20 de octubre de 2020];56(4):106144. D i s p o n i b l e e n : http://www.sciencedirect.com/science/article/pii/S092485 7920303423

25. Magagnoli J, Narendran S, Pereira F, Cummings TH, Hardin JW, Sutton SS, et al. Outcomes of Hydroxychloroquine Usage in United States Veterans Hospitalized with COVID-19. Med [Internet]. 5 de junio de 2020 [citado 6 de noviembre de 2020]; D i s p o n i b l e

e n : http://www.sciencedirect.com/science/article/pii/S266663 4020300064

26. Bakhshaliyev N, Uluganyan M, Enhos A, Karacop E, Ozdemir R. The effect of 5-day course of hydroxychloroquine and azithromycin combination on QT interval in non-ICU COVID19(+) patients. Journal of Electrocardiology [Internet]. 1 de septiembre de 2020 [citado 6 de noviembre de 2020];62:5964 . Disponible e n : http://www.sciencedirect.com/science/article/pii/S002207 3620305288

27. Gautret P, Lagier J-C, Parola P, Hoang VT, Meddeb L, Mailhe M, et al. Hydroxychloroquine and azithromycin as a treatment of COVID-19: results of an open-label non-randomized clinical trial. International Journal of Antimicrobial Agents [Internet]. 1 de julio de 2020 [citado 6 de noviembre de $2020] ; 56(1): 105949$. Disponible en: http://www.sciencedirect.com/science/article/pii/S092485 7920300996

28. Andreani J, Le Bideau M, Duflot I, Jardot P, Rolland C, Boxberger $M$, et al. In vitro testing of combined hydroxychloroquine and azithromycin on SARS-CoV-2 shows synergistic effect. Microbial Pathogenesis [Internet]. 1 de agosto de 2020 [citado 6 de noviembre de 2020];145:104228. Disponible en: http://www.sciencedirect.com/science/article/pii/S088240 1020305155

29. Abd-Elsalam S, Esmail ES, Khalaf M, Abdo EF, Medhat MA, Abd El Ghafar MS, et al. Hydroxychloroquine in the Treatment of COVID-19: A Multicenter Randomized Controlled Study. Am J Trop Med Hyg. 2020;103(4):1635-9.

30. Lyngbakken MN, Berdal J-E, Eskesen A, Kvale D, Olsen IC, Rueegg CS, et al. A pragmatic randomized controlled trial reports lack of efficacy of hydroxychloroquine on coronavirus disease 2019 viral kinetics. Nat Commun. 20 de 2020;11(1):5284.

31. Tang W, Cao Z, Han M, Wang Z, Chen J, Sun W, et al. Hydroxychloroquine in patients with mainly mild to moderate coronavirus disease 2019: open label, randomised controlled trial. BMJ. 14 de 2020;369:m1849.

32. Skipper CP, Pastick KA, Engen NW, Bangdiwala AS, Abassi M, Lofgren SM, et al. Hydroxychloroquine in Nonhospitalized Adults With Early COVID-19 : A Randomized Trial. Ann Intern Med. 20 de 2020;173(8):623-31.

33. Fierabracci A, Arena A, Rossi P. COVID-19: A Review on Diagnosis, Treatment, and Prophylaxis. Int J Mol Sci. 21 de julio de 2020;21(14).

34. Amawi H, Abu Deiab GI, A Aljabali AA, Dua K, Tambuwala MM. COVID-19 pandemic: an overview of epidemiology, pathogenesis, diagnostics and potential vaccines and therapeutics. Ther Deliv. 2020;11(4):245-68.

35. Liu B, Li M, Zhou Z, Guan X, Xiang Y. Can we use interleukin-6 (IL-6) blockade for coronavirus disease 2019 (COVID-19)induced cytokine release syndrome (CRS)? Journal of Autoimmunity. 2020;111:102452.

36. Zhang S, Li L, Shen A, Chen Y, Qi Z. Rational Use of Tocilizumab in the Treatment of Novel Coronavirus Pneumonia. Clin Drug Investig. junio de 2020;40(6):511-8.

37. Bishara D, Kalafatis C, Taylor D. Emerging and experimental treatments for COVID-19 and drug interactions with psychotropic agents. Therapeutic Advances in Psychopharmacology. 2020;10:2045125320935306.

38. Lombardy Section Italian Society Infectious And Tropical Diseases -. Vademecum for the treatment of people with 
COVID-19. Edition 2.0, 13 March 2020. Le Infezioni in Medicina. 1 de junio de 2020;28(2):143-52.

39. Toniati P, Piva S, Cattalini M, Garrafa E, Regola F, Castelli F, et al. Tocilizumab for the treatment of severe COVID-19 pneumonia with hyperinflammatory syndrome and acute respiratory failure: A single center study of 100 patients in Brescia, Italy. Autoimmun Rev. julio de 2020;19(7):102568.

40. Sodani P, Mucci L, Girolimetti R, Tedesco S, Monaco F, Campanozzi D, et al. Successful recovery from COVID-19 pneumonia after receiving baricitinib, tocilizumab, and remdesivir. A case report: Review of treatments and clinical role of computed tomography analysis. Respiratory Medicine Case Reports [Internet]. 1 de enero de 2020 [citado 15 de octubre de 2020];31:101115. Disponible en: http://www.sciencedirect.com/science/article/pii/S221300 7120302574

41. ElSeirafi MM, Hasan HM, Sridharan K, Zamoori A, Alkhawaja S, Pasha SAA. Efficacy and safety of tocilizumab in critically ill adults with COVID-19 infection in Bahrain: A report of 5 cases. Respiratory Medicine Case Reports [Internet]. 1 de enero de 2020 [citado 23 de octubre de 2020];30:101139. Disponible en: http://www.sciencedirect.com/science/article/pii/S221300 7120303440

42. Keske Ş, Tekin S, Sait B, İrkören P, Kapmaz M, Çimen C, et al. Appropriate use of tocilizumab in COVID-19 infection. International Journal of Infectious Diseases [Internet]. 1 de octubre de 2020 [citado 27 de octubre de 2020];99:338-43. D i s p o n i b l e

e $\mathrm{n}$ : http://www.sciencedirect.com/science/article/pii/S120197 1220305804

43. Canziani LM, Trovati S, Brunetta E, Testa A, De Santis M, Bombardieri E, et al. Interleukin-6 receptor blocking with intravenous tocilizumab in COVID-19 severe acute respiratory distress syndrome: A retrospective case-control survival analysis of 128 patients. Journal of Autoimmunity [Internet]. 1 de noviembre de 2020 [citado 20 de octubre de 2020 ]; $114: 102511$. Disponible e n : http://www.sciencedirect.com/science/article/pii/S089684 1120301335

44. Klopfenstein T, Zayet S, Lohse A, Balblanc J-C, Badie J, Royer P$Y$, et al. Tocilizumab therapy reduced intensive care unit admissions and/or mortality in COVID-19 patients. Médecine et Maladies Infectieuses [Internet]. 1 de agosto de 2020 [citado 27 de octubre de 2020];50(5):397-400. Disponible en: http:// www.sciencedirect.com/science/article/pii/S039907 7X20301293

45. Klopfenstein T, Zayet S, Lohse A, Selles P, Zahra H, KadianeOussou NJ, et al. Impact of tocilizumab on mortality and/or invasive mechanical ventilation requirement in a cohort of 206 COVID-19 patients. International Journal of Infectious Diseases [Internet]. 1 de octubre de 2020 [citado 27 de octubre de $2020] ; 99: 491-5$. D is p on ible e n : http:// www.sciencedirect.com/science/article/pii/S120197 1220306536

46. Rossotti R, Travi G, Ughi N, Corradin M, Baiguera C, Fumagalli R, et al. Safety and efficacy of anti-il6-receptor tocilizumab use in severe and critical patients affected by coronavirus disease 2019: A comparative analysis. Journal of Infection [Internet]. 1 de octubre de 2020 [citado 20 de octubre de 2020];81(4):e117. Dis pon ible e n : http://www.sciencedirect.com/science/article/pii/S016344 5320304679

47. Guaraldi G, Meschiari M, Cozzi-Lepri A, Milic J, Tonelli R, Menozzi M, et al. Tocilizumab in patients with severe COVID-19: a retrospective cohort study. The Lancet Rheumatology [Internet]. 1 de agosto de 2020 [citado 20 de octubre de 2020 ]; 2(8):e 474-84. Disponible en: http://www.sciencedirect.com/science/article/pii/S266599 1320301739

48. De Rossi N, Scarpazza C, Filippini C, Cordioli C, Rasia S, Mancinelli CR, et al. Early use of low dose tocilizumab in patients with COVID-19: A retrospective cohort study with a complete follow-up. EClinicalMedicine [Internet]. 1 de agosto de 2020 [citado 27 de octubre de 2020];25:100459. Disponible

http://www.sciencedirect.com/science/article/pii/S258953 7020302030

49. Campochiaro C, Della-Torre E, Cavalli G, De Luca G, Ripa M, Boffini $N$, et al. Efficacy and safety of tocilizumab in severe COVID-19 patients: a single-centre retrospective cohort study. European Journal of Internal Medicine [Internet]. 1 de junio de 2020 [citado 27 de octubre de 2020];76:43-9. Disponible en: http:// www.sciencedirect.com/science/article/pii/S095362 0520301990

50. Biran N, Ip A, Ahn J, Go RC, Wang S, Mathura S, et al. Tocilizumab among patients with COVID-19 in the intensive care unit: a multicentre observational study. The Lancet Rheumatology [Internet]. 1 de octubre de 2020 [citado 20 de octubre de 2020];2(10):e603-12. Disponible en: http://www.sciencedirect.com/science/article/pii/S266599 1320302770

51. Langer-Gould A, Smith JB, Gonzales EG, Castillo RD, Figueroa JG, Ramanathan A, et al. Early identification of COVID-19 cytokine storm and treatment with anakinra or tocilizumab. International Journal of Infectious Diseases [Internet]. 1 de octubre de 2020 [citado 17 de octubre de 2020];99:291-7.
D i s p o n i b l e
e $n:$ http://www.sciencedirect.com/science/article/pii/S120197 1220306093

52. Martínez-Sanz J, Muriel A, Ron R, Herrera S, Pérez-Molina JA, Moreno $\mathrm{S}$, et al. Effects of tocilizumab on mortality in hospitalized patients with COVID-19: a multicentre cohort study. Clinical Microbiology and Infection [Internet]. 23 de septiembre de 2020 [citado 27 de octubre de 2020]; Disponible e

http://www.sciencedirect.com/science/article/pii/S119874 $3 \times 20305735$

53. Mastroianni A, Greco S, Apuzzo G, De Santis S, Oriolo C, Zanolini $A$, et al. Subcutaneous tocilizumab treatment in patients with severe COVID-19-related cytokine release syndrome: An observational cohort study. EClinicalMedicine [Internet]. 1 de julio de 2020 [citado 27 de octubre de 2020];24:100410. D i s p o n i ble e $\mathrm{n}$ : http://www.sciencedirect.com/science/article/pii/S258953 7020301541

54. Kaminski MA, Sunny S, Balabayova K, Kaur A, Gupta A, Abdallah $M$, et al. Tocilizumab therapy for COVID-19: A comparison of subcutaneous and intravenous therapies. International Journal of Infectious Diseases [Internet]. 1 de diciembre de 2020 [citado 27 de octubre de 2020];101:59-64. Disponible en: http://www.sciencedirect.com/science/article/pii/S120197 1220321640

55. Dastan F, Saffaei A, Haseli S, Marjani M, Moniri A, Abtahian Z, et al. Promising effects of tocilizumab in COVID-19: A noncontrolled, prospective clinical trial. International Immunopharmacology [Internet]. 1 de noviembre de 2020 [citado 23 de octubre de 2020];88:106869. Disponible en: http://www.sciencedirect.com/science/article/pii/S156757 6920319032

56. Malekzadeh R, Abedini A, Mohsenpour B, Sharifipour E, Ghasemian R, Javad-Mousavi SA, et al. Subcutaneous tocilizumab in adults with severe and critical COVID-19: A prospective open-label uncontrolled multicenter trial. International Immunopharmacology [Internet]. 1 de diciembre de 2020 [citado 27 de octubre de 2020];89:107102. Disponible http://www.sciencedirect.com/science/article/pii/S156757 6920329192

57. Perrone F, Piccirillo MC, Ascierto PA, Salvarani C, Parrella R, Marata AM, et al. Tocilizumab for patients with COVID-19 pneumonia. The single-arm TOCIVID-19 prospective trial. J Transl Med. 21 de 2020;18(1):405. 
58. Rizk JG, Kalantar-Zadeh K, Mehra MR, Lavie CJ, Rizk Y, Forthal DN. Pharmaco-Immunomodulatory Therapy in COVID-19. Drugs. 21 de julio de 2020;

59. Jamilloux Y, Henry T, Belot A, Viel S, Fauter M, El Jammal T, et al. Should we stimulate or suppress immune responses in COVID-19? Cytokine and anti-cytokine interventions. Autoimmun Rev. julio de 2020;19(7):102567.

60. van de Veerdonk FL, Netea MG. Blocking IL-1 to prevent respiratory failure in COVID-19. Crit Care. 18 de 2020;24(1):445.

61. Stasi C, Fallani S, Voller F, Silvestri C. Treatment for COVID-19: An overview. European Journal of Pharmacology [Internet]. 15 de diciembre de 2020 [citado 15 de octubre de $2020]$; $889: 173644$. Dis pon ible en : http://www.sciencedirect.com/science/article/pii/S001429 9920307366

62. Trpkov C, MacMullan P, Feuchter P, Kachra R, Heydari B, Merchant N, et al. Rapid Response to Cytokine Storm Inhibition using Anakinra in a Patient with COVID-19 Myocarditis. CJC Open [Internet]. 12 de octubre de 2020 [citado 15 de octubre d e $\quad 2 \quad 0 \quad 20$ ]; $\quad$ D i s p o n i b l e e n : http://www.sciencedirect.com/science/article/pii/S258979 0X20301621

63. Filocamo G, Mangioni D, Tagliabue P, Aliberti S, Costantino G, Minoia F, et al. Use of anakinra in severe COVID-19: A case report. International Journal of Infectious Diseases [Internet]. 1 de julio de 2020 [citado 15 de octubre de 2020];96:607-9. D i s p o n i b l e

e $\mathrm{n}$ : http://www.sciencedirect.com/science/article/pii/S120197 1220303337

64. Haigh K, Syrimi ZJ, Irvine S, Blanchard TJ, Pervaiz MS, Toth AG, et al. Hyperinflammation with COVID-19: The key to patient deterioration? Clinical Infection in Practice [Internet]. 1 de octubre de 2020 [citado 20 de octubre de 2020];7-8:100033. D i s p o n i b l e e $\mathrm{n}$ : http://www.sciencedirect.com/science/article/pii/S259017 0220300200

65. Dimopoulos G, de Mast Q, Markou N, Theodorakopoulou M, Komnos A, Mouktaroudi M, et al. Favorable Anakinra Responses in Severe Covid-19 Patients with Secondary Hemophagocytic Lymphohistiocytosis. Cell Host \& Microbe [Internet]. 8 de julio de 2020 [citado 18 de octubre de 2020];28(1):117-123.e1. D i s p o n i b l e

e $\mathrm{n}$ : http://www.sciencedirect.com/science/article/pii/S193131 2820302894

66. Figuero-Pérez L, Olivares-Hernández A, Escala-Cornejo RA, Terán-Brage E, López-Gutiérrez Á, Cruz-Hernández JJ. Anakinra, una alternativa potencial en el tratamiento de la infección respiratoria grave por SARS-CoV-2 refractaria a tocilizumab. Reumatología Clínica [Internet]. 17 de junio de 2020 [citado 19 de octubre de 2020]; Disponible en: http://www.sciencedirect.com/science/article/pii/S169925 8X2030142X

67. Cavalli G, De Luca G, Campochiaro C, Della-Torre E, Ripa M, Canetti D, et al. Interleukin-1 blockade with high-dose anakinra in patients with COVID-19, acute respiratory distress syndrome, and hyperinflammation: a retrospective cohort study. The Lancet Rheumatology [Internet]. 1 de junio de 2020 [citado 20 de octubre de 2020];2(6):e325-31. Disponible en: http://www.sciencedirect.com/science/article/pii/S266599 1320301272

68. Huet T, Beaussier H, Voisin O, Jouveshomme S, Dauriat G, Lazareth I, et al. Anakinra for severe forms of COVID-19: a cohort study. The Lancet Rheumatology [Internet]. 1 de julio de 2020 [citado 19 de octubre de 2020];2(7):e393-400. D i s p o n b l e e n : http://www.sciencedirect.com/science/article/pii/S266599 1320301648

69. Iglesias-Julián E, López-Veloso $\mathrm{M}$, de-la-Torre-Ferrera $\mathrm{N}$, Barraza-Vengoechea JC, Delgado-López PD, Colazo-Burlato M, et al. High dose subcutaneous Anakinra to treat acute respiratory distress syndrome secondary to cytokine storm syndrome among severely ill COVID-19 patients. Journal of Autoimmunity [Internet]. 20 de agosto de 2020 [citado 19 de octubre de 2020];102537. Disponible en: http://www.sciencedirect.com/science/article/pii/S089684 1120301633

70. Seif F, Aazami H, Khoshmirsafa M, Kamali M, Mohsenzadegan M, Pornour M, et al. JAK Inhibition as a New Treatment Strategy for Patients with COVID-19. Int Arch Allergy Immunol. 2020;181(6):467-75.

71. Zhang X, Zhang Y, Qiao W, Zhang J, Qi Z. Baricitinib, a drug with potential effect to prevent SARS-COV-2 from entering target cells and control cytokine storm induced by COVID-19. Int Immunopharmacol. 1 de julio de 2020;86:106749.

72. Ceribelli A, Motta F, De Santis M, Ansari AA, Ridgway WM, Gershwin ME, et al. Recommendations for coronavirus infection in rheumatic diseases treated with biologic therapy. J Autoimmun. 2020;109:102442.

73. Magro G. SARS-CoV-2 and COVID-19: is interleukin-6 (IL-6) the «culprit lesion» of ARDS onset? What is there besides Tocilizumab? SGP130Fc. Cytokine X. 14 de mayo de 2020;100029.

74. Saber-Ayad M, Saleh MA, Abu-Gharbieh E. The Rationale for Potential Pharmacotherapy of COVID-19. Pharmaceuticals (Basel). 14 de mayo de 2020;13(5).

75. Cingolani A, Tummolo AM, Montemurro G, Gremese E, Larosa L, Cipriani MC, et al. Baricitinib as rescue therapy in a patient with COVID-19 with no complete response to sarilumab. Infection [Internet]. 1 de octubre de 2020 [citado 26 de noviembre de 2020];48(5):767-71. Disponible en: https: / / doi.org/10.1007/s15010-020-01476-7

76. Titanji BK, Farley MM, Mehta A, Connor-Schuler R, Moanna A, Cribbs SK, et al. Use of Baricitinib in Patients With Moderate to Severe Coronavirus Disease 2019. Clin Infect Dis [Internet]. [citado 26 de noviembre de 2020]; Disponible en: h t t p s : / / a cademic.oup.com / cid / advance article/doi/10.1093/cid/ciaa879/5864596

77. Cantini F, Niccoli L, Matarrese D, Nicastri E, Stobbione P, Goletti D. Baricitinib therapy in COVID-19: A pilot study on safety and clinical impact. J Infect [Internet]. agosto de 2020 [citado 26 de noviembre de 2020];81(2):318-56. Disponible en: https://www.ncbi.nlm.nih.gov/pmc/articles/PMC7177073/

78. FDA Authorizes Baricitinib Combo for COVID-19 [Internet]. Medscape. [citado 25 de noviembre de 2020]. Disponible en: http://www.medscape.com/viewarticle/941324. 